\title{
EVALUASI PROGRAM INDONESIA SEHAT DENGAN PENDEKATAN KELUARGA DAN IMPLEMENTASI KEGIATAN TENAGA KESEHATAN BERSINERGI BERSAMA UNTUK MASYARAKAT SEHAT
}

\author{
Asma Suhada $^{1}$, Arif Budiwitarto ${ }^{2}$, Zulkieflimannsyah $^{3}$, Mukhammad Najib $^{4}$, \\ Kahar Karim $^{5}$
}
${ }^{1}$ Pascasarjana Universitas Teknologi Sumbawa, Sumbawa, undaasma@gmail.com ${ }^{2}$ Pascasarjana Universitas Teknologi Sumbawa,witarto@uts.ac.id
${ }^{3}$ Pascasarjana Universitas Teknologi Sumbawa, zulkieflimansyah@uts.ac.id ${ }^{4}$ Pascasarjana Universitas Teknologi Sumbawa,najib@ipb.ac.id ${ }^{5}$ Pascasarjana Universitas Teknologi Sumbawa, kaharkarim@uts.ac.id

\begin{tabular}{ll|lll}
\hline Article history & \multicolumn{1}{l}{} \\
\hline Dikirim tanggal & $: 10 / 03 / 2020$ & Diterima tanggal & $:$ & $02 / 09 / 2020$ \\
Revisi pertama tanggal & $: 18 / 08 / 2020$ & Tersedia online tanggal & $:$ & $29 / 09 / 2020$ \\
\hline
\end{tabular}

\begin{abstract}
ABSTRAK
Pembangunan kesehatan merupakan salah satu agenda dari program Nawa Cita yaitu meningkatkan kualitas hidup manusia Indonesia melalui Program Indonesia Sehat dengan tujuan untuk meningkatkan kesadaran, kemauan dan kemampuan hidup sehat bagi setiap orang untuk meningkatan derajat kesehatan yang setinggi-tingginya. Program Indonesia sehat dengan pendekatan keluarga merupakan upaya untuk menjawab tantangan pembangunan kesehatan tersebut. hasil dari pendataan Program Indonesia Sehat Pendekatan Keluarga akan menjadi salah satu acuan dalam merencanakan manajemen puskesmas. Tujuan penelitian ini adalah untuk mengevaluasi pelaksanaan kegiatan Program Indonesia Sehat dengan Pendekatan Keluarga dan implementasi TAKASIMURAH di UPT Puskesmas Kecamatan Labuhan Badas. Metode yang digunakan adalah kualitatif deskriptif dengan tehnik pengumpulan data berupa wawancara, observasi dan studi dokumen. Hasil penelitian menunjukkan bahwa pelaksanaan kegiatan Program Indonesia Sehat dengan Pendekatan Keluarga sudah cukup optimal dilaksanakan dan implementasi TAKASIMURAH mampu meningkatkan capaian program sesuai 12 indikator yang ditetapkan. Hasil penelitian ini diharapkan akan menjadi acuan oleh puskesmas lain dalam meningkatkan pelayanan menggunakan inovasi yang sama
\end{abstract}

Kata kunci: Pendekatan Keluarga, Program Indonesia Sehat, Telehealt

\section{ABSTRACT}

Indonesia Program, increase awareness, willingness, and ability to live healthy lives for everyone to improve their health status as high as possible. The healthy Indonesia program with a family approach is an effort to respond to these health development challenges. The results of the Healthy Indonesia Family Approach Program will be one of the references in planning the management of health centers.

This study was to observe the implementation of the Healthy Indonesia Program with the Family Approach and the performance of TAKASIMURAH at The Health Center of Labuhan Badas District. The method used is descriptive qualitative data collection techniques as interviews, observation, and study of documents. The results show, the Healthy Indonesia Program activities with the Family Approach optimally implemented, and the performance of TAKASIMURAH was able to increase program achievements according to 12 indicators set. The results of this study are expecting to be a reference by other health centers in improving services using the same innovation.

Keywords: Healthy Indonesia Program; Family approach; Telehealt 


\section{PENDAHULUAN}

Kondisi kesehatan masyarakat Indonesia saat ini semakin kompleks. Berdasarkan hasil Riset Kesehatan Dasar (Riskesdas) tahun 2018 prevalensi beberapa penyakit semakin meningkat beserta faktor risikonya. Meskipun beberapa indikator juga mengalami peningkatan, namun belum mencapai target SDG's, sehingga diperlukan upaya pembangunan kesehatan. Pembangunan kesehatan merupakan salah satu agenda dari program Nawa Cita yaitu meningkatkan kualitas hidup manusia Indonesia melalui Program Indonesia Sehat. Program Indonesia Sehat dengan pendekatan Keluarga (PISPK) merupakan salah satu cara Pusat Kesehatan Masyarakat (Puskesmas) untuk meningkatkan jangkauan sasaran dan mendekatkan akses pelayanan kesehatan di wilayah kerjanya. PIS-PK di tingkat puskesmas dilaksanakan melalui kegiatan (1) melaksanakan pendataan kesehatan semua anggota kelurga, (2) membuat dan mengelola pangkalan data Puskesmas, (3) menganalisis, merumuskan intervensi masalah kesehatan dan menyusun rencana Puskesmas, (4) melakukan kunjungan rumah dalam kegiatan promotif, preventif, kuratif dan rehabilitative, (5) melakukan pelayanan kesehatan (dalam dan luar) melalui pendekatan siklus hidup dan (6) melakukan Sistem Informasi dan Pelaporan Puskesmas. PIS-PK dilaksanakan dengan mengintergrasikan dalam manajemen Puskesmas (Kementerian Kesehatan, 2016).

UPT Puskesmas Kecamatan Labuhan Badas merupakan FKTP yang bertanggung jawab atas kesehatan masyarakat di wilayah Kecamatan Labuhan Badas. Berdasarkan Permenkes No. 75 tahun 2014 Puskesmas juga menyelenggarakan program UKP dan UKM. Berdasarkan laporan tahunan program, pada tahun 2017 yang diambil sesuai dengan 12 indikator yaitu 79,2\% keluarga mengikuti program Keluarga Berencana (KB), 87,6\% ibu melakukan persalinan di fasilitas kesehatan, 94,3\% bayi mendapat imunisasi dasar lengkap, 89,5\% bayi mendapat air susu ibu (ASI), 84,16 balita mendapatkan pemantauan pertumbuhan, 53\% penderita tuberculosis paru mendapatkan pengobata sesuai standart, 1365 penderita hipertensi melakukan pengobatan secara teratur, 14 penderita gangguan jiwa mendapatkan pengobatan dan tidak ditelantarkan, 128 anggota keluarga tidak ada yang merokok, 19.790 keluarga sudah menjadi anggota JKN, 5269 keluarga memunyai akses sarana air bersih dan 5065 keluarga mempunyai akses atau menggunakan jamban sehat Berdasarkan Surat Keputusan Kepala Dinas Kesehatan kabupatan Sumbawa bahwa UPT Puskesmas Kecamatan Labuhan Badas sebagai lokus dilakukannya PIS-PK.

UPT Puskesmas Kecamatan Labuhan Badas telah melakukan rangkaian kegiatan yaitu pendataan keluarga yang merupakan langkah awal PIS-PK. Tujuan pendataan keluarga adalah untuk memperoleh data kesehatan setiap keluarga khususnya data mengenai 12 indikator sebagai penanda status kesehatan keluarga untuk perencanaan di puskesmas. Hasil pendataan yang dilakukan sampai dengan bulan Januari 2019 didapatkan sebanyak 58.02\% keluarga mengikuti program Keluarga Berencana (KB), $96,50 \%$ ibu melakukan persalinan di fasilitas kesehatan, $92,26 \%$ bayi mendapat imunisasi dasar lengkap, 92,27\% bayi mendapat air susu ibu (ASI), 91,89 balita mendapatkan pemantauan pertumbuhan, $21,24 \%$ penderita tuberculosis paru mendapatkan pengobata sesuai standart, 30,68\% penderita hipertensi melakukan pengobatan secara teratur, $40 \%$ penderita gangguan jiwa mendapatkan pengobatan dan tidak ditelantarkan, 35,49\% anggota keluarga tidak ada yang merokok, 42,77\% keluarga sudah menjadi anggota JKN, 97,23\% keluarga memunyai akses sarana air bersih dan $87,41 \%$ keluarga mempunyai akses atau menggunakan jamban sehat dan Indeks 
Keluarga Sehat 0,17\%. UPT BLUD Puskesmas Kecamatan Labuhan Badas telah melakukan intervensi awal berupa penyuluhan sesuai masalah yang ditemukan.

Perencanaan puskesmas berdasarkan hasil pendataan PIS-PK akan direncanakan menggunakan teknologi informasi dan komunikasi yang saat ini sudah banyak digunakan oleh kalangan masyarakat. Pengelolaan masalah kesehatan tidak hanya berfokus pada pelayanan medis, namun diintegrasikan dengan promosi, preventif yang dapat dilakukan oleh semua tenaga kesehatan, sehingga manajemen puskesmas perlu menggunakan teknologi yang berkembang saat ini untuk memenuhi pelayanan kesehatan sehingga meningkatkan capaian dan mengatasi jarak antara tenaga kesehatan dengan masyarakat.menggunakan media teknologi komunikasi. Teknologi komunikasi yang dapat digunakan sebagai metode baru dalam memberikan dukungan pelayanan kesehatan di masyarakat adalah menggunakan handphone dengan memanfaatkan SMS sosial media seperti whatsapp dengan masyarakat.

Berdasarkan uraian di atas peneliti tertarik untuk melakukan penelitian dengan judul "Evaluasi Implementasi Kegiatan Program Indonesia Sehat Pendekatan Keluarga di UPT Puskesmas Kecamatan Labuhan Badas".

\section{TINJAUAN LITERATUR}

Program Indonesia Sehat yang dasar pelaksanakannya dilaksanakan pada PERMENKES 39 Tahun 2016 merupakan salah satu program dari Agenda ke-5 Nawa Cita, yaitu Meningkatkan Kualitas Hidup Manusia Indonesia. Program ini didukung oleh program sektoral lainnya yaitu Program Indonesia Pintar, Program Indonesia Kerja, dan Program Indonesia Sejahtera. Program Indonesia Sehat selanjutnya menjadi program utama Pembangunan Kesehatan yang kemudian direncanakan pencapaiannya melalui Rencana Strategis Kementerian Kesehatan Tahun 2015-2019, yang ditetapkan melalui Keputusan Menteri Kesehatan R.I. Nomor HK.02.02/Menkes/52/2015.

Sasaran dari Program Indonesia Sehat adalah meningkatnya derajat kesehatan dan status gizi masyarakat melalui upaya kesehatan dan pemberdayaan masyarakat yang didukung dengan perlindungan finansial dan pemerataan pelayanan kesehatan. Konsep Keluarga Pendekatan keluarga adalah salah satu cara Puskesmas untuk meningkatkan jangkauan sasaran dan mendekatkan/meningkatkan akses pelayanan kesehatan di wilayah kerjanya dengan mendatangi keluarga. Puskesmas tidak hanya menyelenggarakan pelayanan kesehatan di dalam gedung, melainkan juga keluar gedung dengan mengunjungi keluarga di wilayah kerjanya.

Pendekatan keluarga merupakan pengembangan dari kunjungan rumah oleh puskesmas dan perluasan dari upaya Perawatan Kesehatan Masyarakat (Perkesmas), yang meliputi kegiatan : (1) Kunjungan keluarga untuk pendataan/pengumpulan data Profil Kesehatan Keluarga dan peremajaan (updating) pangkalan data; (2) Kunjungan keluarga dalam rangka promosi kesehatan sebagai upaya promotif dan preventif; (3) Kunjungan keluarga untuk menindaklanjuti pelayanan kesehatan; (4) Pemanfaatan data dan informasi dari profil kesehatan keluarga untuk pengorganisasian/pemberdayaan masyarakat dan manajemen puskesmas.

Pelaksanaan PIS-PK merupakan kegiatan terintegrasi, sehingga semua pihak bertanggung jawab terhadap terlaksananya PIS-PK. Monitoring dan evaluasi PIS-PK dilakukan secara berjenjang sesuai dengan tugas dan fungsi masing-masing level penanggung jawab. Evaluasi dilaksanakan untk memastikan PISPK berjalan sesuai regulasi serta menilai kemajuan implementasi PIS-PK dalam rangka mewujudkan Indonesia Sehat. 
Evaluasi PIS-PK dilakukan pada tahapan: (1) Pelaksanaan Pelatihan Keluarga Sehat dalam mendukung PIS-PK; (2) Pelaksanaan persiapan PIS-PK; (3) Pelaksanaan Kunjungan Keluarga dan Intervensi Awal PIS-PK; (4) Pelaksanaan Analisis Indeks Keluarga Sehat (IKS) awal; (5) Pelaksanaan Intervensi Lanjut PIS-PK.

Intervensi lanjut yang direncanakan berdasarkan hasil PIS PK adalah menggunakan media smartphone untuk melakukan promosi dan prevensi yaitu Telehaealt. Menurut The Health Resources Service Administration, telehealth merupakan penggunaan teknologi informasi dan komunikasi elektronik guna mendukung layanan kesehatan jarak-jauh, edukasi penghubung pasien dan profesi kesehatan, serta urusan administrasi kesehatan masyarakat. Dengan cara ini, layanan konsultasi kesehatan dapat dilakukan tanpa harus langsung ketemu dokter, namun dapat dilakukan secara tatap muka. Berbagai macam layanan fasyankes daerah dapat lebih efektif dilakukan dengan dukungan telehealth. Teknologi ini dapat membantu fasyankes di daerah dengan kondisi geomorfologi bisa terhubung dengan pasien yang berjarak jauh. System ini juga mendukung terciptanya layanan pasien mandiri

\section{METODE PENELITIAN}

Jenis penelitian ini adalah penelitian kualitatif deskriptif. Penelitian ini dilakukan pada tanggal 26 Februari sampai dengan 24 Maret 2019 di UPT Puskesmas Kecamatan Labuhan Badas. Data yang digunakan dalam penelitian ini ada dua macam yaitu data primer dan data sekunder. Data primer merupakan data yang diperoleh langsung oleh peneliti di UPT Puskesmas Kecamatan Labuhan Badas sebagai obyek penelitian. Sedangkan data sekunder adalah data yang didapat melalui dokumen RUK, Renstra Puskesmas, Profil Kesehatan dan Laporan Hasil PIS-PK. Data primer dari penelitian ini diambil langsung dari responden dan informan melalui wawancara dan observasi mengenai perencanaan kegiatan berdasarkan hasil PIS-PK terhadap mekanisme perencanaan program kerja. sedangkan data sekunder diperoleh dari dokumentasi, naskah, profil, RUK dan dokumen lain yang berkaitan dengan penelitian ini.

\section{HASIL PENELITIAN}

\section{Pelaksanaan persiapan kegiatan pendataan Program Indonesia Sehat dengan Pendataan Keluarga}

a. Kebijakan

Program Indonesia Sehat dengan Pendekatan Keluarga (PIS PK) di UPT Puskesmas Kecamatan Labuhan Badas berdasarkan hasil wawancara dan penelusuran dokumentasi sudah mempunyai SK Bupati, SK Kepala Dinas Kesehatan maupun SK Kepala Puskesmas. Sosialisasi Permenkes No. 39 tahun 2016 tentang Penyelenggaraan Program Indonesia Sehat dengan Pendekatan Keluarga kepada seluruh tenaga Puskesmas dan lintas sektor dilakukan pada tahun 2017 yang dihadiri oleh 10 orang tenaga kesehatan dan 15 orang lintas sektor yang terdiri dari Camat, Kepala Desa serta Kader dengan menggunakan anggaran dari APBN (BOK).

Sosialisasi Permenkes No. 44 tahun 2016 tentang Pedoman Manajemen Puskesmas kepada 40 orang pegawai puskesmas dilaksanakan pada bulan Februari Tahun 2018. Tim pelaksana ditunjuk oleh Kepala Puskesmas sebagai koordinator PIS PK yang terdiri dari penanggung jawab UKM, UKP dan program baik esensial maupun 
pengembangan dengaan alasan supaya penanggung jawab program mendapatkan target sasaran program yang nyata untuk dijadikan acuan pelaksanaan kegiatan program.

\section{b. Sumber Daya Manusia}

Sumber Daya Manusia telah disiapkan oleh UPT Puskesmas Kecamatan Labuhan Badas dalam persiapan pelaksanaan PIS PK. Berdasarkan hasil wawancara dan penelusuran dokumentasi sudah dibentuk 5 tim yang berjumlah 25 orang. Puskesmas telah memiliki tenaga yang dilatih Manajemen Puskesmas sesuai kurikulum modul tahun 2016.

\section{c. Sarana dan Prasarana}

Pelaksanaan program PIS PK di UPT Puskesmas Kecamatan Labuhan Badas di dukung oleh sarana dan prasarana. Berdasarkan hasil wawancara, telah disiapkan sarana dan prasarana namun kurang memadai untuk melaksanakan kegiatan PIS PK yang bersumber dari dana APBN (BOK) sehingga menggunakan alat pribadi pada saat kunjungan rumah. Telah disusun perencanaan kebutuhan sarana dan prasarana melalui ASPAK dengan tetap memperhatikan integrasi sumber daya.

\section{d. Pencatatan dan Pelaporan}

Instrument yang digunakan dalam melaksanakan kunjungan keluarga PIS PK di UPT Puskesmas Kecamatan Labuhan Badas menggunakan Form Prokesga dengan sumber biaya cetak melalui dana APBD (BOK) dan menggunakan Aplikasi KS dalam menginput hasil pendataan dengan menggunakan nomer akun (username dan password) yang didapat dari pusdatin kemenkes. Namun dalam pelaksanaan terdapat hambatan yaitu jaringan internet yang lambat

\section{Pelaksanaan kunjungan keluarga dan intervensi awal}

Pelaksanaan kunjungan dan intervensi awal telah dilakukan oleh UPT Puskesmas Kecamatan Labuhan Badas. Jumlah KK yang ada di UPT Puskesmas Kecamatan Labuhan Badas adalahPelaksanaan kunjungan diawali dengan dibentuknya tim Pembina keluarga dan sosialisasi Permenkes No. 39 tahun 2016 tentang Penyelenggaraan Program Indonesia Sehat dengan Pendekatan Keluarga sehingga seluruh staf puskesmas memahami konsep PIS PK. Berdasarkan hasil kuesioner didapatkan sekitar 50\% staf telah memahami konsep PIS PK. Dalam melakukan kunjungan awal instrument yang digunakan adalah form prokesga yang dicetak melalui pembiayaan APBN (BOK). Puskesmas juga menyediakan Pinkesga paket berupa leaflet dan brosur dalam memberikan informasi kesehatan kepada keluarga yang mempunyai masalah kesehatan berdasarkan temuan. Alat-alat kesehatan juga disediakan oleh puskesmas dalam melakukan kunjungan keluarga seperti alat pengukur tekanan darah dan stetoskop namun jumlahnya masih belum mencukupi sehingga menggunakan alat pribadi. Dalam pelaksanaan kunjungan, petugas kesehatan dapat mengukur tekanan darah dan melakukan pembacaan hasil pengukuran menggunakan alat yang tersedia. Hasil pengukuran yang menunjukkan tekanan darah yang meningkat dilakukan intervensi lanjut di Puskesmas. Pendataan satu KK membutuhkan waktu rata-rata 60 menit. Bedasarkan hasil wawancara dan observasi belum seluruh wilayah kerja Puskesmas dilakukan kunjungan. Individu dalam keluarga yang dilakukan kunjungan telah diidentifikasi masalah kesehatannya sesuai 12 indikator. 
Rekapitulasi kunjungan dapat dilihat dalam table dibawah ini.

Tabel 4.1 Rekapitulasi Kunjungan Keluarga

UPT Puskesmas Kecamatan Labuhan Badas Tahun 2019

\begin{tabular}{|c|c|c|c|c|c|}
\hline \multirow{2}{*}{$\begin{array}{c}\text { Jumlah KK } \\
\text { dilakukan } \\
\text { kunjungan } \\
\text { keluarga }\end{array}$} & \multirow{2}{*}{$\begin{array}{c}\text { Jumlah KK } \\
\text { yang sudah } \\
\text { lengkap } \\
\text { diperoleh } \\
\text { data }\end{array}$} & \multirow{2}{*}{$\begin{array}{c}\text { Jumlah KK } \\
\text { yang belum } \\
\text { lengkap } \\
\text { diperoleh } \\
\text { data } \\
\end{array}$} & \multicolumn{3}{|c|}{ Jumlah KK telah memiliki IKS } \\
\hline & & & Tidak sehat & Pra sehat & Sehat \\
\hline $\begin{array}{c}7123 \\
(88,8 \%)\end{array}$ & $\begin{array}{c}6677 \\
(93,7 \%)\end{array}$ & $\begin{array}{c}446 \\
(6,5 \%)\end{array}$ & $\begin{array}{c}2267 \\
(33,9 \%)\end{array}$ & $\begin{array}{c}3933 \\
(58,9 \%)\end{array}$ & $\begin{array}{c}477 \\
(7,2 \%)\end{array}$ \\
\hline
\end{tabular}

Sumber data: Aplikasi KS, 2019

Table 4.1menyatakan bahwa jumlah KK yang dilakukan kunjungan belum memenuhi total coverage yaitu sebanyak $7123(88,8 \%)$ dari total KK yang ada di wilayah kerja UPT Puskesmas Kecamatan Labuhan Badas yaitu 8.023. Total KK yang sudah lengkap diperoleh data sebanyak 93,7\% dengan Indeks Keluarga Sehat (IKS) tidak sehat sebesar 33,9\%, Pra Sehat sebesar $58,9 \%$ dan Sehat sebesar 7,2\%.

Tabel 4.2 Rekapitulasi Masalah Kesehatan 12 Indikator Keluarga Sehat dan Intervensi Awal UPT Puskesmas Kecamatan Labuhan Badas Tahun 2019

\begin{tabular}{|c|c|c|c|c|c|}
\hline \multirow[t]{2}{*}{ No } & \multirow[t]{2}{*}{ Indikator } & \multicolumn{2}{|c|}{$\begin{array}{l}\text { Jumlah yang } \\
\text { bermasalah }\end{array}$} & \multicolumn{2}{|c|}{$\begin{array}{c}\text { Jumlah yang } \\
\text { diberikan intervensi } \\
\text { awal } \\
\end{array}$} \\
\hline & & Individu & KK & Individu & KK \\
\hline 1 & Keluarga mengikuti KB & 4770 & 2385 & 2384 & 1192 \\
\hline 2 & Ibu melakukan persalinan di faskes & 116 & 116 & 58 & 58 \\
\hline 3 & $\begin{array}{l}\text { Bayi mendapatkan Imunisasi Dasar } \\
\text { Lengkap }\end{array}$ & 129 & 129 & 70 & 70 \\
\hline 4 & $\begin{array}{l}\text { Bayi diberi ASI Eksklusif selama } 6 \\
\text { bulan }\end{array}$ & 181 & 181 & 181 & 181 \\
\hline 5 & $\begin{array}{l}\text { Memantau pertumbuhan balita tiap } \\
\text { bulan }\end{array}$ & 692 & 692 & 450 & 450 \\
\hline 6 & Penderita TB Paru berobat teratur & 84 & 84 & 48 & 48 \\
\hline 7 & Penderita hipertensi berobat teratur & 605 & 605 & 300 & 300 \\
\hline 8 & $\begin{array}{l}\text { Gangguan jiwa berat tidak } \\
\text { ditelantarkan }\end{array}$ & 23 & 23 & 13 & 13 \\
\hline 9 & $\begin{array}{l}\text { Tidak ada anggota keluarga yang } \\
\text { merokok }\end{array}$ & 2889 & 2889 & 2400 & 2400 \\
\hline 10 & $\begin{array}{l}\text { Keluarga mempunyai akses atau } \\
\text { memiliki sarana air bersih }\end{array}$ & 2887 & 2887 & 1500 & 1500 \\
\hline 11 & $\begin{array}{l}\text { Keluarga mempunyai akses atau } \\
\text { memiliki jamban sehat }\end{array}$ & 2888 & 2888 & 1120 & 1220 \\
\hline 12 & Sekeluarga menjadi anggota JKN & 11430 & 2886 & 5400 & 5400 \\
\hline
\end{tabular}

Sumber data: Aplikasi KS, 2019 
Tabel 4.2, menunjukkan jumlah individu dan KK yang bermasalah dan dilakukan intervensi awal

Tabel 4.3 Rekapitulasi Masalah Kesehatan di luar 12 Indikator Keluarga Sehat dan Intervensi Awal

UPT Puskesmas Kecamatan Labuhan Badas Tahun 2019

\begin{tabular}{|c|l|c|c|c|c|}
\hline \multirow{2}{*}{ No } & \multirow{2}{*}{ Indikator } & \multicolumn{2}{c|}{$\begin{array}{c}\text { Jumlah yang } \\
\text { bermasalah }\end{array}$} & \multicolumn{2}{c|}{$\begin{array}{c}\text { Jumlah yang diberikan } \\
\text { intervensi awal }\end{array}$} \\
\cline { 3 - 6 } & & Individu & KK & Individu & KK \\
\hline 1 & Diabetes Mellitus & 28 & 28 & 14 & 14 \\
\hline 2 & Hipotensi & 230 & 145 & 120 & 120 \\
\hline 3 & Asma & 30 & 30 & 15 & 15 \\
\hline 4 & Down Sindrom & 7 & 7 & 7 & 7 \\
\hline 5 & Stroke & 2 & 2 & 2 & 2 \\
\hline 6 & Gastritis & 6 & 6 & 6 & 6 \\
\hline 7 & Hepatitis & 3 & 3 & 3 & 3 \\
\hline 8 & Gagal Ginjal Kronis & 3 & 3 & 3 & 3 \\
\hline 9 & Epilepsi & 3 & 3 & 3 & 3 \\
\hline 10 & Leukimia & 1 & 1 & 1 & 1 \\
\hline 11 & Gout Atritis & 8 & 8 & 8 & 8 \\
\hline
\end{tabular}

Sumber data: Aplikasi KS, 2019

Tabel 4.3 menunjukkan penyakit diluar dari indicator yang ditemukan pada saat dilakukan pendataan

Berdasarkan hasil kuesioner, bahwa tim Pembina keluarga sehat puskesmas melakukan pembinaan terhadap keluarga di wilayah UPT Puskesmas Kecamatan Labuhan Badas sebanyak 1 kali/bulan dan telah melakukan kunjungan ulang sebanyak 2-3 kali kepada 70 KK. Tim Pembina keluarga telah melakukan rekapitulasi permasalahan KS dan melakukan intervensi lanjut terhadap permasalahan yang ditemukan. Selanjutnya dilakukan rujukan ke puskesmas dalam rangka intervensi lanjutan dari hasil kunjungan keluarga terhadap permasalahan indikator keluarga sehat atau permasalahan kesehatan lainnya. Berdasarkan hasil kuesioner kasus yang paling banyak dilakukan rujukan baik ke puskesmas maupun ke fasilitas rujukan tingkat lanjut adalah dengan hipertensi.

\section{Perencanaan kegiatan implementasi TAKASIMURAH}

Berdasarkan hasil pendataan PIS-PK, maka peneliti mencoba membuat perencanaan kegiatan intervensi untuk mengatasi 12 indikator masalah kesehatan yang ditemukan. Intervensi yang direncanakan yaitu Telehealth- tenagA KesehAtan berSInergi bersaMa Untuk masyaRAkat seHat (TAKASIMURAH) dengan tahapan perencanaan yaitu yang pertama dimulai dari persiapan yaitu mengadakan pertemuan dengan staf puskesmas terutama tenaga kesehatan untuk melibatkan dalam perencanaan intervensi yang dilakukan agar memperoleh kesamaan pandangan dan pengetahuan untuk melaksanakan tahap perencanaan. dengan analisis SWOT.

Kegiatan TAKASIMURAH ini disosialisaikan ke lintas sector dan juga masyarakat dalam kegiatan minilokakarya yang rutin di adakan oleh puskesmas kemudia disosialisasikan ke masyarakat melalui kader-kader kesehatan. Pelaksanaan TAKASIMURAH yang dilaksanakan diobservasi melalui laporan capaian program yang diserahkan oleh pemegang program kepada Ka. TU untuk dilakukan penilaian kinerja setiap 1 bulan, 3 bulan, 6 bulan dan setahun dan sepengetahuan kepala UPT Puskesmas untuk merencanakan kegiatan dibulan berikutnya atau di tahun berikutnya 
Setelah dilaksanakan program TAKASIMURAH didapatkan hasil capaian program mengalami peningkatan capaian, karena tahun 2019 baru sampai pada triwulan 2 sehingga perbandingan capaian dilihat pada perbandingan program dalam triwulan pertama sejak tahun 2017, 2018 dan 2019.

Gambar 1. Perbandingan capaian program tahun 2017,2018,2019
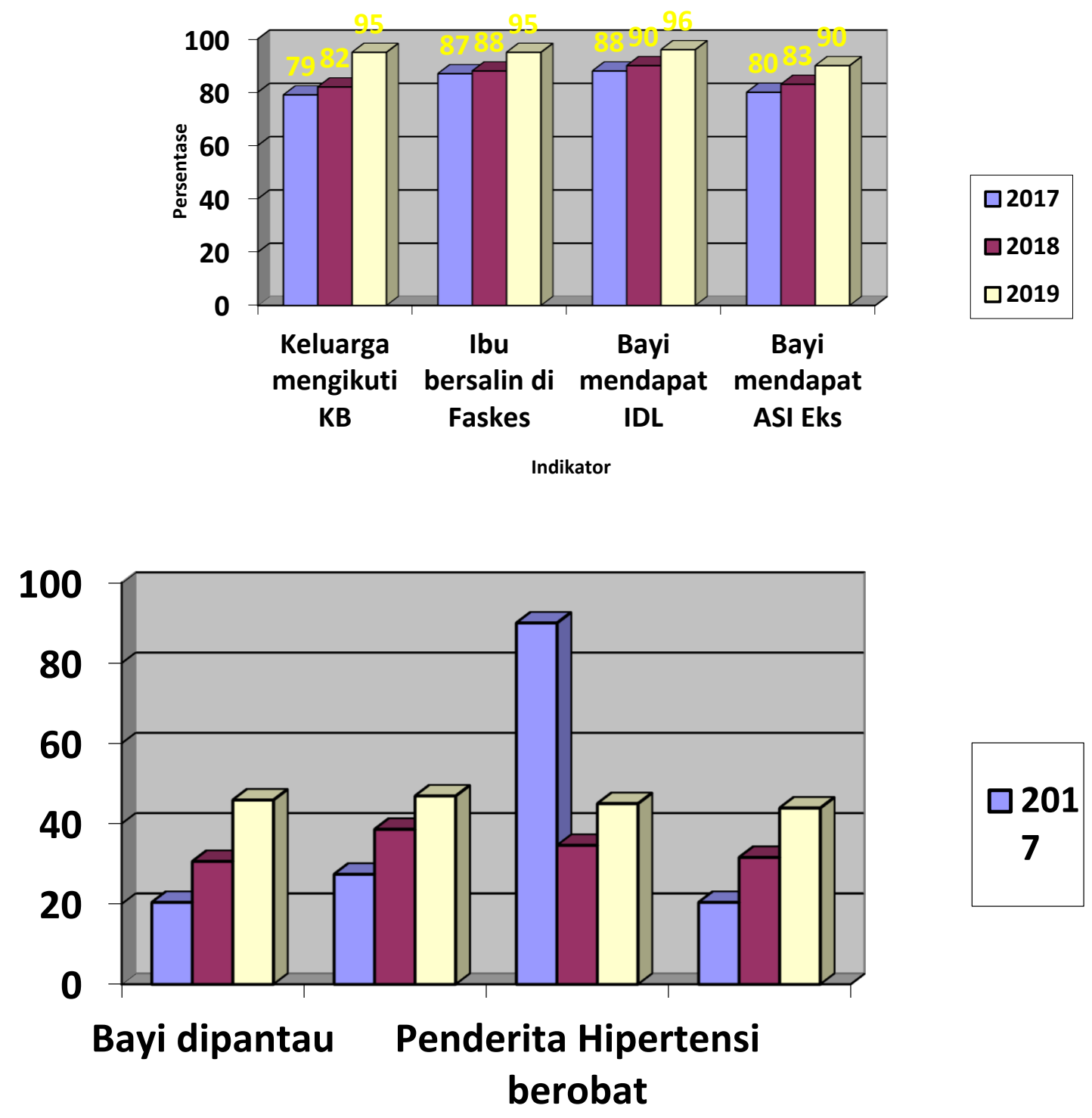


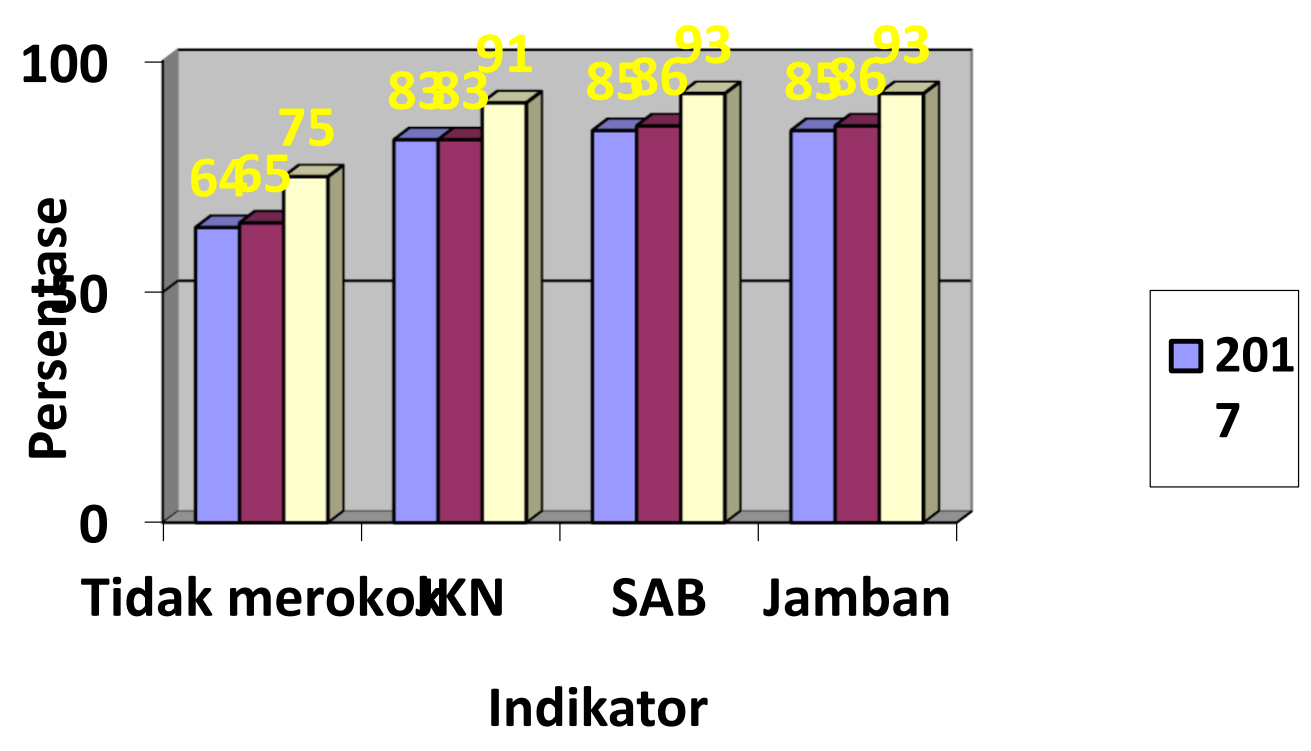

Gambar 1 menampilkan perbandingan capaian program berdasarkan 12 indikator sebelum dan sesudah adanya inovasi TAKASIMURAH. Indikator keluarga mengikuti KB pada tahun 2017 sebesar 79\%, mengalami peningkatan tahun 2018 sebesar $82 \%$ dan setelah ada inovasi TAKASIMURAH meningkat sebesar 95\%. Indikator Ibu bersalin di fasilitas kesehatan pada tahun 2017 sebesar 87\%, mengalami peningkatan tahun 2018 sebesar $88 \%$ dan setelah ada inovasi TAKASIMURAH meningkat sebesar 95\%. Indikator bayi mendapat Imunisasi Dasar Lengkap pada tahun 2017 sebesar 88\%, mengalami peningkatan tahun 2018 sebesar $90 \%$ dan setelah ada inovasi TAKASIMURAH meningkat sebesar 96\%. Bayi mendapatkan ASI Ekslusif pada tahun 2017 sebesar 80\%, mengalami peningkatan tahun 2018 sebesar 83\% dan setelah ada inovasi TAKASIMURAH meningkat sebesar 90\%. Bayi mendapatkan pemantauan pada tahun 2017 sebesar 82\%, mengalami peningkatan tahun 2018 sebesar $83 \%$ dan setelah ada inovasi TAKASIMURAH meningkat sebesar 92\%.

Penderita TB yang menjalani pengobatan pada tahun 2017 sebesar 50\%, mengalami peningkatan tahun 2018 sebesar 65\% dan setelah ada inovasi TAKASIMURAH meningkat sebesar 75\%. Penderita Hipertensi yang menjalani pengobatan pada tahun 2017 sebesar 80\%, mengalami peningkatan tahun 2018 sebesar $85 \%$ dan setelah ada inovasi TAKASIMURAH meningkat sebesar 96\%. Penderita ODGJ pada tahun 2017 sebesar 60\%, mengalami peningkatan tahun 2018 sebesar $75 \%$ dan setelah ada inovasi TAKASIMURAH meningkat sebesar $85 \%$. Indicator keluarga tidak merokok pada tahun 2017 sebesar 64\%, mengalami peningkatan tahun 2018 sebesar $65 \%$ dan setelah ada inovasi TAKASIMURAH meningkat sebesar $75 \%$. Keluarga peserta JKN pada tahun 2017 sebesar 83\%, mengalami peningkatan tahun 2018 sebesar $83 \%$ dan setelah ada inovasi TAKASIMURAH meningkat sebesar $91 \%$. Penggunaan sarana air bersih pada tahun 2017 sebesar 85\%, mengalami peningkatan tahun 2018 sebesar $86 \%$ dan setelah ada inovasi TAKASIMURAH meningkat sebesar $92 \%$. Penggunaan jamban pada tahun 2017 sebesar 85\%, mengalami peningkatan tahun 2018 sebesar 86\% dan setelah ada inovasi TAKASIMURAH meningkat sebesar 93\%.

Rata-rata peningkatan capaian pada tahun 2017 sebesar 3\% meningkat pada tahun 2018. Setelah ada program TAKASIMURAH terjadi peningkatan $8 \%$ pada tahun 2019 dari capaian tahun 2018. 


\section{PEMBAHASAN}

\section{Pelaksanaan persiapan kegiatan pendataan Program Indonesia Sehat dengan Pendataan Keluarga}

Program Indonesia sehat pendekatan keluarga (PIS-PK) merupakan kegiatan yang diamanatkan dalam rencana strategis kementerian kesehatan tahun 2015-2019 (Kementerian Kesehatan, 2016). PIS-PK dilaksanakan oleh puskesmas sesuai dengan amanat dalam rencana strategis yang dibuat mengacu pada renstra Dinas Kesehatan dan Kementerian Kesehatan. Puskesmas melaksanakan kegiatan PIS-PK telah membuat perencanaan yang akan menjadi arahan bagi kegiatan yang akan dilaksanakan. Perencanaan PIS-PK tingkat puskesmas terdiri dari pelaksanaan persiapan kegiatan pendataan, pelaksaaan kunjungan keluarga dan intervensi awal. Pelaksanaan persiapan kegiatan pendataan diawali dengan adanya kebijakan dan sosialisasi baik internal maupun eksternal, penetapan penanggung jawab atau koordinator PIS-PK, adanya koordinator dan tim pembinan keluarga di puskesmas, ketersediaan anggaran yang terintegrasi untuk pelaksanaan PIS-PK, tersedianya formulir dan pinkesga, tersedianya roadmap pemenuhan kebutuhan untuk pelayanan kesehatan serta tersedianya sarana dan prasarana seperti alat kesehatan pada puskesmas yang menjadi lokus PIS-PK.

Menurut Evans \& Manning (2003), kebijakan merupakan suatu konsensus atau kesepakatan terhadap suatu persoalan, dimana sasaran dan tujuannya diarahkan pada suatu prioritas yang bertujuan dan memiliki petunjuk utama untuk mencapainya. Menurut Seymond (2007) bahwa kebijakan dalam perencanaan strategis akan memberikan arahan bagi kegiatan yang akan dilakukan. Hal ini ditunjukkan dengan adanya kebijakan yang harus ada dalam pelaksanaan PIS-PK yang meliputi SK Bupati/Walikota, SK Kadinkes, SK Kepala Puskesmas, Permenkes Nomor 44 Tahun 2016 tentang pedoman manajemen puskesmas, Permenkes Nomor 39 tahun 2016 tentang Pedoman Penyelenggaraan Program Indonesia Sehat dengan Pendekatan Keluarga. Surat Keputusan (SK) merupakan dasar hukum dari suatu tindakan, kegiatan, kondisi ataupun fungsi status yang dijadikan legal aspek dalam melaksanakan program. Kesiapan puskesmas dalam melaksanakan kegiatan PIS-PK ditunjukkan oleh perencanaan program yang matang. Berdasarkan hasil wawancara dan penelusuran dokumentasi UPT Puskesmas Kecamatan Labuhan Badas sudah mempunyai SK Bupati, SK Kepala Dinas Kesehatan maupun SK Kepala Puskesmas. Dalam penelitian Evi et al (2018) bahwa jika program dilaksanakan tanpa adanya surat keputusan maka akan membuat pelaksanaan yang baik tidak bisa diharapkan. Petugas akan melakukan pekerjaan menurut pemahamannya sendiri.

Sosialisasi merupakan proses belajar seorang anggota masyarakat untuk mengenal dan menghayati kebudayaan masyarakat di lingkungannya. Berdasarkan Permenkes No. 39 tahun 2016 tentang Penyelenggaraan Program Indonesia Sehat dengan Pendekatan Keluarga yang menyebutkan bahwa pendataan harus dilakukan kepada seluruh keluarga di wilayah kerja puskesmas (total coverage), sehingga harus dilakukan sosialisasi kepada seluruh tenaga Puskesmas dan lintas sektor. Berdasarkan hasil wawancara sosialisasi Permenkes No 39 Tahun 2016 dan Permenkes No. 44 tahun 2016 tentang Pedoman Manajemen Puskesmas kepada pegawai puskesmas, lintas sector dan tokoh masyarakat dilaksanakan oleh puskesmas. Puskesmas telah menunjukkan komitmen untuk melaksanakan PIS PK yaitu dengan dibentuknya tim yang ditunjuk oleh Kepala Puskesmas untuk kegiatan pendataan PIS PK. Berdasarkan hasil penelitian Badan Penelitian dan Pengembangan Kesehatan (2017) menyatakan bahwa sosialisasi 
eksternal sangat dibutuhkan untuk mendapatkan dukungan camat, kepala desa dan jajarannya. Hal ini dilakukan untuk keperluan listing rumah tangga di desa/RW/RT/dusun secara riil untuk pengorganisasian lapangan dan diperlukan dalam membantu sosialisasi kepada masyarakat terkait pendataan keluarga oleh petugas sehingga diharapkan tidak ada lagi penolakan warga terhadap kehadiran petugas.

Puskesmas telah menyiapkan Sumber Daya Manusia yang telah dilatih agar pelaksanaan pendataan sesuai dengan petunjuk dari pusat. Berdasarkan hasil wawancara, tim yang sudah dibentuk sebanyak 5 tim berjumlah 25 orang. Tenaga yang dilatih yaitu 5 orang dan mendapatkan pelatihan di provinsi sesuai kurikulum. Hal ini sesuai dengan Leggat et al (2011) bahwa sistem kerja dalam organisasi membutuhkan investasi sumber daya manusia yang dapat dilakukan melalui pelatihan. Menurut Kurniadi (2007), pelatihan berfungsi untuk memberikan bekal keterampilan guna mendukung tugas-tugas dalam suatu organisasi sehingga tercapai tujuan dan sasaran yang telah ditentukan. Pelatihan selain memberikan keterampilan juga meningkatkan prestasi kerja bagi SDM kesehatan karena bekerja sesuai dengan pedoman (Lumbanraja \& Nizma, 2010).

SDM yang telah dilatih oleh provinsi memahami konsep PIS PK dengan baik dan dapat melaksanakan program atau sistem kerja dengan baik. Tenaga yang tidak dilatih hanya mendapatkan informasi dari kegiatan sosialisasi misalnya pada saat pelaksanaan minilokakarya puskesmas sehingga kurang memahami konsep, tujuan serta mekansme pelaksanaan pendataan PIS PK. Sehingga SDM yang sudah mengikuti pelatihan tetap mendampingi SDM lain yang ditugaskan namun dengan pemahaman terbatas tentang PIS PK.

Jumlah SDM yang ditunjuk untuk pelaksanaan PIS PK masih belum sesuai dengan rasio jumlah penduduk. SDM yang ditunjuk mempunyai tugas pokok di puskesmas, akibatnya pendataan PIS PK hanya dijadikan sebagai tugas tambahan dan tidak semua kegiatan PIS PK bisa dilakukan sesuai dengan pedoman pelaksanaan PIS PK seperti pemberian informasi kesehatan maupun penyuluhan kesehatan. Sejalan dengan hasil penelitian markus (2018) bahwa beban tugas sehari-hari sudah menyita tenaga dan waktu sehingga sulit apabila ditambahkan dengan tugas melaksanakan PIS PK.

Selain SDM, dalam pelaksanaan PIS PK juga dibutuhkan sarana dan prasarana. Sarana dan prasarana yang dibutuhkan dalam melaksanakan PIS-PK sesuai dengan pedoman terdiri dari Prokesga, Pinkesga, computer, koneksi internet, tensimeter, stetoskop, family folder, ruang penyimpanan, alat transportasi, id card, alat tulis, aplikasi dan stiker. Berdasarkan hasil wawancara kebutuhan akan sarana dan prasarana telah disiapkan dan kurang memadai untuk melaksanakan kegiatan PIS-PK yang bersumber dari dana APBN (BOK) namun telah disusun perencanaan kebutuhan sarana dan prasarana melalui ASPAK dengan tetap memperhatikan integrasi sumber daya. Sebagian petugas masih menggunakan alat pribadi untuk melakukan pendataan, misalnya tesnsimeter dan stetoskop.

Pendataan PIS-PK dilakukan menggunakan instrument yang dilaksanakan pada saat kunjungan keluarga PIS PK. UPT Puskesmas Kecamatan Labuhan Badas menggunakan Form Prokesga dengan sumber biaya cetak melalui dana APBD (BOK) dan menggunakan Aplikasi KS dalam menginput hasil pendataan dengan menggunakan nomer akun (username dan password) yang didapat dari pusdatin kemenkes. Namun dalam pelaksanaan terdapat hambatan yaitu jaringan internet yang lambat. Kegiatan PIS-PK yang dilakukan dilakukan pencatatan dan pelaporan oleh puskesmas sesuai dengan format yang telah disediakan. Berdasarkan pedoman, pencatatan dan pelaporan 
dilakukan menggunakan instrument yaitu form Prokesga dan diinput dalam aplikasi keluarga sehat baik versi android maupun website. Berdasarkan hasil wawancara, Pendataan PIS-PK dilakukan menggunakan instrument yang dilaksanakan pada saat kunjungan keluarga PIS PK. UPT Puskesmas Kecamatan Labuhan Badas menggunakan Form Prokesga dengan sumber biaya cetak melalui dana APBD (BOK) dan menggunakan Aplikasi KS dalam menginput hasil pendataan dengan menggunakan nomer akun (username dan password) yang didapat dari pusdatin kemenkes. Namun dalam pelaksanaan terdapat hambatan yaitu jaringan internet yang lambat dan sering eror. Berdasarkan hasil penelitian Kuntum (2018) yang menyatakan bahwa faktor penghambat pelaksanaan PIS-PK dari segi sumber daya yaitu fasilitas dan infrastruktur program yang ada

\section{Pelaksanaan kunjungan keluarga dan intervensi awal}

Pendataan PIS-PK dilakukan dengan cara melakukan kunjungan rumah melalui pendekatan keluarga di wilayah kerja puskesmas berdasarkan petunjuk tehnis. Kunjungan rumah dilakukan oleh petugas yang ditunjuk sebagai tim oleh puskesmas. Kunjungan rumah dilaksanakan untuk menentukan status kesehatan keluarga apakah sehat atau tidak dengan mengacu pada 12 indikator utama sebagai penanda status kesehatan. Dalam melaksanakan kunjungan rumah tersebut ada tiga hal yang harus diperhatikan yaitu instrument yang digunakan di tingkat keluarga, orum komunikasi, keterlibatan tenaga dari masyarakat.

Berdasarkan hasil wawancara bahwa pelaksanaan kunjungan dan intervensi awal telah dilakukan oleh UPT Puskesmas Kecamatan Labuhan Badas. Pelaksanaan kunjungan diawali dengan dibentuknya tim Pembina keluarga dan sosialisasi Permenkes No. 39 tahun 2016 tentang Penyelenggaraan Program Indonesia Sehat dengan Pendekatan Keluarga sehingga seluruh staf puskesmas memahami konsep PIS PK. Berdasarkan hasil kuesioner didapatkan sekitar 50\% staf telah memahami konsep PIS PK. Puskesmas juga menyediakan Pinkesga paket berupa leaflet dan brosur dalam memberikan informasi kesehatan kepada keluarga yang mempunyai masalah kesehatan berdasarkan temuan namun jumlahnya terbatas. Alat-alat kesehatan juga disediakan oleh puskesmas dalam melakukan kunjungan keluarga seperti alat pengukur tekanan darah dan stetoskop namun jumlahnya masih belum mencukupi sehingga menggunakan alat pribadi. Dalam pelaksanaan kunjungan, petugas kesehatan dapat mengukur tekanan darah dan melakukan pembacaan hasil pengukuran menggunakan alat yang tersedia yang hasilnya akan dilakukan intervensi lanjut di Puskesmas. Pendataan satu KK membutuhkan waktu rata-rata 60 menit. Bedasarkan hasil wawancara dan observasi belum seluruh wilayah kerja Puskesmas dilakukan kunjungan. Individu dalam keluarga yang dilakukan kunjungan telah diidentifikasi masalah kesehatannya sesuai 12 indikator.

Berdasarkan hasil kuesioner, bahwa tim Pembina keluarga sehat puskesmas melakukan pembinaan terhadap keluarga di wilayah UPT Puskesmas Kecamatan Labuhan Badas sebanyak 1 kali/bulan dan telah melakukan kunjungan ulang sebanyak 2-3 kali kepada $70 \mathrm{KK}$. Hal ini dilakukan diluar jam kerja karena pada jam kerja melaksanakan tugas pokok yang dibebankan. Tim Pembina keluarga telah melakukan rekapitulasi permasalahan KS dan melakukan intervensi lanjut terhadap permasalahan yang ditemukan. Selanjutnya dilakukan rujukan ke puskesmas dalam rangka intervensi lanjutan dari hasil kunjungan keluarga terhadap permasalahan indikator keluarga sehat atau permasalahan kesehatan lainnya. Berdasarkan hasil kuesioner kasus yang paling 
banyak dilakukan rujukan baik ke puskesmas maupun ke fasilitas rujukan tingkat lanjut adalah dengan hipertensi.

Dengan keterbatasan sarana prasarana dan tenaga, pendataan PIS-PK tetap dilakukan karena adanya komitmen tinggi dari tim yang telah dibentuk. Leggat, et al (2011) bahwa praktik high performance work system yang berlaku dalam suatu pengorganisasian mempegaruhi kinerja dengan meningkatkan pengetahuan, keterampilan, kemampuan dan komitmen karyawan dengan cara memberi nformasi dan kebijaksanaan yang diperlukan untuk memanfaatkan keterampilan dan komitmen dalam melaksanakan pekerjaan mereka.

Berdasarkan table 4.1, rekapitulasi kunjungan keluarga belum memenuhi total coverage. Berdasarkan table 4.2, rekapiltulasi 12 indikator masalah kesehatan, yang dilakukan intervensi kurang lebih masih 50\%. Menurut Seymond (2007), dalam melaksanakan intervensi, diperlukan kerjasama lintas sector maupun program dengan bidangbagian yang terkait dengan kegiatan tersebut. selain itu perencanaan strategis dilakukan dengan menggali sumber daya yang ada, termasuk upaya keterpaduan antara pemegang program dan dukungan politis pemerintah daerah, pihak swasta dan partisipasi masyarakat untuk dijadikan sebagai suatu kekuatan dan peluang mencapai kebutuhan local. Demikian halnya dengan pelaksanaan pendatan dan intervensi awal PIS-PK dibutuhkan dukungan lintas sector demi kelancaran kegiatan. Sosialisasi penting untuk dilakukan mengenai kegiatan dan manfaat PIS-PK lepada masyarakat sehingga memudahkan akses pada saat kunjungan rumah.

\section{Perencanaan kegiatan intervensi TAKASIMURAH}

Dengan diterbitkannya permenkes no 39 tahun 2016, pemerintah telah menetapkan bahwa puskesmas merupakan ujung tombak dan penentu keberhasilan pelaksanaan program ini. Adapun area prioritas dalam program ini disusun dalam 12 indikator masalah kesehatan. Pelaksanaannya melalui upaya promotif dan preventif tanpa mengabaikan upaya kuratif dan rehabilitative. pendekatan keluarga adalah pendekatan pelayanan puskesmas yang menggabungkan upaya kesehatan perseorangan dan upaya kesehatan masyarakat secara berkesinambungan dengan didasarkan pada informasi dan data dari profil kesehatan keluarga. Melalui pendekatan keluarga dapat ditangani masalah kesehatan individu secara siklus hidup melalui kerjasama antar tenaga kesehatan yang ada di puskesmas. Hal ini sesuai dengan rencana strategis kementerian kesehatan RI dimana penerapan pelayanan kesehatan harus terintegrasi dan berkesinambungan.

Salah satu bentuk intervensi yang direncanakan oleh peneliti yaitu TAKASIMURAH adalah kerjasama antara tenaga kesehatan dalam melakukan kunjungan rumah dan penggunaan teknologi informasi dan komunikasi elektronik guna mendukung layanan kesehatan jarak-jauh, edukasi penghubung pasien dan profesi kesehatan, serta urusan administrasi kesehatan masyarakat dalam mengatasi masalah kesehatan sesuai indikator yang ditetapkan. Kerjasama antar pogram dan tenaga kesehatan akan meningkatkan penyelesaian terhadap masalah-masalah kesehatan melalui upaya promotif dan preventif. Program ini secara tidak langsung akan menguatkan manajemen puskesmas secara internal mencakup sumber daya manusia, pendanaan, sarana dan prasarana, program kesehatan, system informasi dan jejaring pihak terkait dilingkup kerja puskesmas.

Sesuai dengan penelitian Fu \& Liu, 2015 yang menyatakan bahwa implementasi pelayanan kesehatan menggunakan smartphone baik dalam memberikan edukasi maupun tindakan keperawatan meningkatkan kepuasan pasien dan mengurangi waktu 
menunggu perawat sehingga menguntungkan pasien, keluarga dan perawat itu sendiri. Dalam sebagian besar penelitian penggunaan smartphone lebih popular digunakan untuk perawatan pasien yang bertujuan untuk mendukung manajemen layanan kesehatan, karena penggunaan teknologi smartphone lebih banyak daripada teknologi lainnya. Beberapa negara menggunakan smartphone sebagai strategi untuk memaksimalkan sistem perawatan kesehatan dan pencarian layanan kesehatan (Nagel \& Penner, 2016). Penelitian lain juga menyatakan bahwa menggunakan handphone dan smartphone untuk merawat pasien dengan penyakit kronis terutama di daerah yang letaknya jauh dari tempat pelayanan kesehatan dapat memudahkan komunikasi perawat dengan pasien, memberikan keamanan pada petugas dan pasien yang tidak harus menempuh jarak yang jauh saat membutuhkan bantuan perawat dan respon dari petugas menjadi lebih cepat (Marin et al., 2016).

Keberhasilan program ini tentunya memerlukan pemahaman dan komitmen yang sungguh-sungguh, sistematis dan terencana dari seluruh petugas puskesmas. Kesamaan pemahaman dan komitmen yang kuat akan menghasilkan tercapainya target area prioritas/sasaran dari program yang direncanakan. Komitmen untuk bekerja di dalam dan di luar gedung puskesmas tentu juga perlu didukung oleh dinas kesehatan sebagai induk dari puskesmas.

\section{SIMPULAN DAN SARAN}

\section{Simpulan}

Secara umum pelaksanaan kegiatan pendataan keluarga di UPT Puskesmas Kecamatan Labuhan Badas cukup optimal karena sesuai dengan pedoman dan rencana yang telah ditetapkan. Pelaksanaan pendataan keluarga sudah cukup baik dalam pencapaian hasil. Hal tersebut dapat ditinjau dari: sudah terbentuknya tim oleh puskesmas dan sudah diterbitkan SK tentang kebijakan PIS-PK baik oleh dinas kesehatan maupun kepala UPT Puskesmas, terdapat SDM yang sudah dilatih sesuai pedoman, ketersedian dana yang cukup yang dialokasikan kepada petugas yang menjalankan kegiatan pendataan, sarana dan prasarana sudah disediakan meskipun belum mencukupi, pencatatan dan pelaporan dalam aplikasi meskipun masih terkendala oleh jaringan internet yang lambat.

Kegiatan implementasi yang direncanakan oleh peneliti (TAKASIMURAH) dibuat berdasarkan hasil dari 12 indikator masalah kesehatan berdasarkan hasil pendataan PIS PK, dan dibuat berdasarkan hasil analisis SWOT sehingga didapatkan strategi untuk menyelesaikan masalah kesehatan yang ada melalui sinergitas tenaga kesehatan dalam melakukan pendekatan keluarga melalui upaya promotif dan preventif. Rata-rata peningkatan capaian pada tahun 2017 sebesar 3\% meningkat pada tahun 2018. Setelah ada program TAKASIMURAH terjadi peningkatan $8 \%$ pada tahun 2019 dari capaian tahun 2018.

Kegiatan TAKASIMURAH ini dapat meningkatkan cakupan dan kualitas pelayanan kesehatan dengan pendekatan keluarga, meningkatnya ketersediaan data dan informasi di bidang kesehatan, meningkatkan koordinasi dengan lintas program, lintas sector, profesi/organisasi profesi, organisasi masyarakat, dunia usaha, media massa dan pihak terkait, meningkatnya peran serta dan pemberdayaan keluarga, masyarakat dalam 
upaya peningkatan kesehatan lanjut usia, memperpendek jarak antara petugas kesehatan dengan masyarakat

\section{Saran}

Diharapkan puskesmas melakukan kemitraan dengan kader kesehatan serta tokoh masyarakat untuk membantu dalam memperlancar kegiatan pendataan maupun intervensi awal, melakukan sosialisasi lebih lanjut kepada warga yang belum mendapatkan informasi mengenai kegiatan PIS-PK, menjalin komunikasi dan koordinasi dengan perangkat desa supaya dapat mensosialisasikan kepada warga sehingga mengurangi kendala dalam pendataan PISPK dan pelaksanaan intervensi awal, puskesmas membuat jadwal dan target kegiatan pendataan keluarga untuk setip harinya sehingg dapat mempercepat pencapaian total coverage, mengoptimalkan penggunaan dana PISPK sesuai denga pedoman pendanaan, adanya monitoring dan evaluasi terhadap pelaksanaan PIS-PK.

\section{REFERENSI}

Andi Pratowo. 2011. Metode Penelitian Kualitatif. Yogyakarta: Ar-Ruzz Media.

Arikunto, S. 2010. Prosedur penelitian: Suatu Pendekatan Praktik. (Edisi. Revisi). Jakarta: Rineka Cipta.

BurhanBungin. 2003. Analisis Data Penelitian Kualitatif. Jakarta: PT. Rajagrafindo Persada.

Convelo G. Cevilla, dkk., 2003. Pengantar Metode Penelitian, Jakarta: Universitas Indonesia.

Fu, Z., \& Liu, K. (2015). Application of a Smartphone Nurse Call System for Nursing Care, 21(2), 105-109. https://doi.org/10.1089/tmj.2014.0071

Hasan, M. Iqbal. 2002. Pokok-pokok Materi Metodologi Penelitian dan Aplikasinya. Ghalia Indonesia, Bogor.

Laelasari, dkk (2017). Evaluasi Kesiapan Pelaksanaan Program Indonesia Sehat Dengan Pendekatan Keluarga. Badan Litbang Kesehatan

Nagel, D. A., \& Penner, J. L. (2016). Conceptualizing Telehealth in Nursing Practice, 91-104.

Marin, X., Epelde, A., Segalés, M., Arjona, M., Clopés, M., Serra, E., \& Palou, M. (2016). Efficacy of a smartphone app (WhatsICS) for communication amongst health care professionals attending patients with chronic diseases, 16(6), 8-9.

Moleong, (2007). Metodologi Penelitian Kualitatif, Bandung, Remaja Karya

Sugiyono. 2008. Metode Penelitian Kunatitatif Kualitatif dan $R \& D$. Bandung. Alfabeta. 
Sutopo, H. B. 2002. Metode Penelitian Kualitatif, Dasar Teori dan Terapannya dalam Penelitian. Surakarta: UNS Press.

Peraturan menteri kesehatan Nomor 75 tahun 2014 tentang puskesmas

Peraturan Menteri kesehatan nomor 44 tahun 2016 tentang manajemen puskesmas 